\title{
Changes in the epidemiological pattern of Mycoplasma pneumoniae infections in Denmark
}

\author{
A 30 years survey \\ BY K. LIND ${ }^{1}$ AND M. W. BENTZON ${ }^{2}$ \\ ${ }^{1}$ Mycoplasma Laboratory and ${ }^{2}$ Biostatistical Department, Statens Seruminstitut, \\ Amager Boulevard 80, DK-2300 Copenhagen S., Denmark
}

(Accepted 10 May 1988)

\section{SUMMARY}

A seroepidemiological survey has shown a remarkable shift in the previously reported regular cyclic pattern of Mycoplasma pneumoniae epidemics which culminated every $4 \cdot 5$ years during the period 1958-74. The last of four regular epidemics occurred in 1972. It was followed by 'premature' epidemics in 1975 and $1977 / 8$ which inaugurated a change from an epidemic to an endemic pattern of the infection in Denmark. Over the following 9 years $(1978-86)$ there has been an irregular but significant decrease in the annual number of seropositive samples with the usual high incidence during winter seasons. This endemic period terminated in the fourth trimester of 1987 with the development of a new epidemic. The hypothesis is advanced that a sixfold increase of children in day care may have influenced the change from an epidemic to an endemic situation which after 9 years led to a new epidemic of $M$. pneumoniae infection.

\section{INTRODUCTION}

Mycoplasma pneumoniae is a common cause of lower respiratory tract disease in humans. In most countries the disease is prevalent all year round, with a relatively high incidence during winter. Longitudinal studies indicate that the incidence varies markedly from year to year (Chanock et al. 1967; Evans, Allen \& Sueltmann, 1967; Foy et al. 1979; Glezen et al. 1971; Joosting et al. 1976).

In a previous serological investigation of the incidence of $M$. pneumoniae infection in Denmark during the 17-year period 1958-74 we found that four epidemics had occurred, which culminated at regular intervals of 4.5 years (Lind \& Bentzon, 1976). The present serological investigation was carried out over the following 13 years until the end of February 1988. From this it appears that there has been a change of the epidemiological pattern of $M$. pneumoniae infections in this country, which took place over the years 1972-8. Since then the infection had been endemic with a trend of decreasing incidence until the fourth trimester of 1987 when a new epidemic started. 


\section{SAMPLE AND METHODS}

During the 30 years of the study all blood specimens were received at the same central laboratory serving all hospitals and general practitioners in Denmark. The main purpose for the submission of specimens was to confirm the diagnosis of what was first called cold agglutinin positive primary atypical pneumonia or Eaton Agent pneumonia. (Eaton, Meiklejohn \& Herick, 1944; Chanock et al. 1961). Later on, as knowledge of the disease increased, more specific serological tests in the diagnosis of $M$. pneumoniae infection became available (Clyde, 1979).

In the years January 1958 to November 1973 all specimens were tested by cold agglutinin (CA) and Streptococcus MG agglutinin titrations (Lind, 1968), and CA positive sera were stored at $-20^{\circ} \mathrm{C}$ for further study. As described previously (Lind, 1971; Lind \& Bentzon, 1976) frozen sera, representative of each month, were randomly selected and tested for antibodies to $M$. pneumoniae. Briefly, the majority of sera from 1958 to September 1969 were tested by an indirect immunofluorescence (IF) test. In the following years this test was supplemented first by an indirect haemagglutination (IHA) test and later by a complement fixation (CF) test which has been used almost exclusively since January 1970, and exclusively since 1973 (Lind \& Bentzon, 1976).

Through the 30 years from 1958-87 the population has increased in a linear fashion from 4.5 to $5 \cdot 1$ million inhabitants.

\section{Serological methods}

The CF test for antibodies to $M$. pneumoniae was performed according to the method of Kenny \& Grayston (1965), slightly modified as described in detail in an appendix to a previous article (Lind \& Bentzon, 1976). Since June 1985 the test has been performed in a microtitre system equilibrated to give results with reference sera similar to the 'macro'-method, and using the same titre of $\geqslant 64$ as the criterion for a positive result. In each set-up two pools of patients' sera, one with a high titre and one with a medium high titre, together with a negative serum, were included. The Mac strain, isolated in 1944 (Eaton, Meiklejohn \& Herick, 1944), was used throughout the entire period for the preparation of a chloroform-methanol extracted glycolipid antigen. This strain was processed between the 35th and 60th passages. There was no correlation between number of passages and titre of antigen.

Throughout all 30 years the CA test was carried out on all serum samples, before 1969 as described by Lind, Mansa \& Olesen (1963), and since 1970 by a slightly modified procedure (Lind \& Bentzon, 1976). In each test the two pools of patients' sera, both positive with respect to $\mathrm{CA}$, and the negative serum, have been included as controls.

As a test for day-to-day reproducibility of both the $\mathrm{CF}$ and the CA test, the results of tests on positive reference sera from four periods were randomly chosen, one from 1976-7, the others from 1984-5. From each period consecutive test results were analysed, representing a total of 327 test days. The standard deviation for both positive reference sera was between 0.53 and 0.60 dilution step in the CF test, and between 0.62 and 0.77 in the CA test. A test to monitor for trends over each period showed no significant fall or rise of titres. 

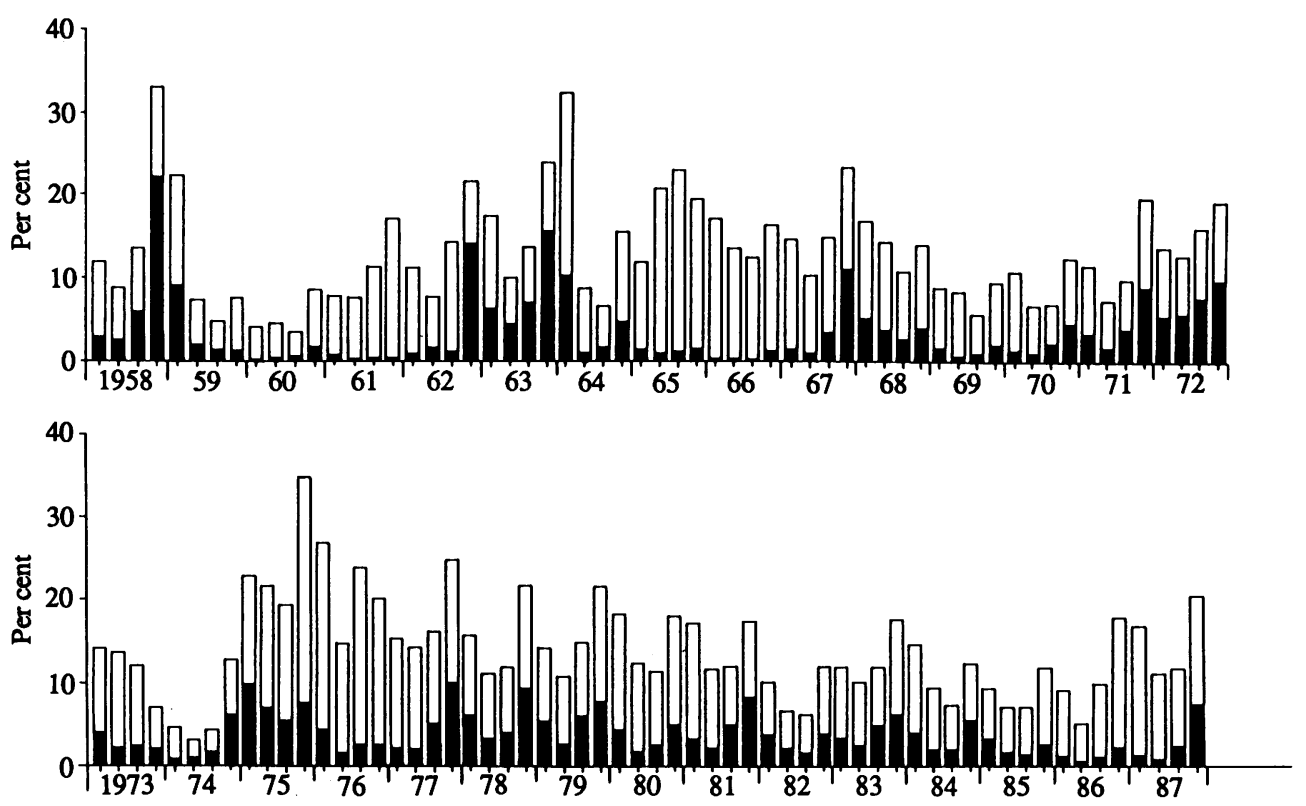

口 Percentage of cold agglutinin-positive sera per trimester out of total investigated.

- Percentage of $M$. pneumoniae antibody-positive and cold agglutinin-positive sera per trimester out of total investigated.

Fig. 1. The columns show samples of serum with a positive cold agglutinin (CA) test, and the black part of the columns are those with a positive CA test plus a positive anti$M$. pneumoniae test only, both given as percentages of all sera investigated in each trimester in the period $1958-87$.

\section{Statistical methods}

The periodicity in the frequency of seropositive samples from the period 1958-74 was investigated by means of a multiple regression analysis as described earlier (Lind \& Bentzon, 1976). For other periods a two-way analysis of variance model was found to give a better fit. Such an analysis was therefore used to test the variations from year to year and the seasonal variations.

\section{RESULTS}

The annual number of blood specimens received increased from approximately 4000 in 1958 to over 20000 in 1987. The increase has been stepwise, and each major step has coincided with an increase in number of specimens showing a positive anti-M. pneumoniae test plus a positive cold agglutinin test, indicating epidemics of $M$. pneumoniae infection (see discussion).

In Fig. 1 the columns show samples of serum with a positive CA test, and the black part of the columns are those with a positive CA test plus a positive anti$M$. pneumoniae test, both given as percentages of all sera investigated in each trimester in the period 1958-87. The frequency of seropositive samples from the period 1958-74 corresponds well with four major waves (Lind \& Bentzon, 1976). Two of these which culminated in 1963 and in 1972, respectively, also show 
Table 1. Annual number of serum samples tested for cold agglutinins (CA) and M. pneumoniae (MP) antibodies over a period of 30 years

\begin{tabular}{|c|c|c|c|c|c|c|c|c|}
\hline \multirow[b]{2}{*}{ Year } & \multirow{2}{*}{$\begin{array}{l}\text { Total } \\
\text { number } \\
\text { investi- } \\
\text { gated }\end{array}$} & \multicolumn{2}{|c|}{ CA positive } & \multicolumn{2}{|c|}{$\begin{array}{l}\text { Anti-MP positive } \\
\text { plus ('A positive }\end{array}$} & \multicolumn{2}{|c|}{ Anti-MP positive } & \multirow{2}{*}{$\begin{array}{l}\text { Anti-MP pos. } \\
\text { plus (A pos. } \\
\text { in } \% \text { of } \\
\text { all anti-MP } \\
\text { positive }\end{array}$} \\
\hline & & Number & $\begin{array}{c}\% \text { of all } \\
\text { sera }\end{array}$ & Number & $\begin{array}{c}\% \text { of all } \\
\text { sera }\end{array}$ & Number & $\begin{array}{c}\% \text { of all } \\
\text { sera }\end{array}$ & \\
\hline 1958 & 4395 & 822 & $18 \cdot 7$ & $432 \mathrm{c}$ & $9 \cdot 83$ & - & - & - \\
\hline 1959 & 4219 & 524 & $12 \cdot 4$ & $178 \mathrm{c}$ & $4 \cdot 19$ & - & - & - \\
\hline 1960 & 3771 & 197 & $5 \cdot 2$ & $25 \mathrm{c}$ & $0 \cdot 66$ & - & - & - \\
\hline 1961 & 3854 & 438 & $11 \cdot 4$ & $16 \mathrm{c}$ & 0.42 & - & - & - \\
\hline 1962 & 4597 & 644 & $14 \cdot 0$ & $222 \mathrm{c}$ & $4 \cdot 83$ & - & $\ldots$ & - \\
\hline 1963 & 5947 & 1023 & $17 \cdot 2$ & $530 c$ & $8 \cdot 91$ & - & - & - \\
\hline 1964 & 6247 & 1156 & $18 \cdot 5$ & $331 \mathrm{c}$ & $5 \cdot 30$ & - & - & - \\
\hline 1965 & 5932 & 1110 & $18 \cdot 7$ & $77 \mathrm{c}$ & $1 \cdot 30$ & - & - & - \\
\hline 1966 & 6387 & 977 & $15 \cdot 3$ & $34 \mathrm{c}$ & 0.53 & - & - & 一 \\
\hline 1967 & 6704 & 1126 & $16 \cdot 8$ & $330 \mathrm{c}$ & $4 \cdot 92$ & - & - & - \\
\hline 1968 & 7819 & 1137 & $14 \cdot 5$ & $322 \mathrm{c}$ & $4 \cdot 12$ & - & - & - \\
\hline 1969 & 7103 & 600 & $8 \cdot 4$ & $92 c$ & $1 \cdot 30$ & - & - & - \\
\hline 1970 & 6317 & 611 & $9 \cdot 7$ & $140 c$ & $2 \cdot 22$ & - & - & - \\
\hline 1971 & 7423 & 985 & $13 \cdot 2$ & $377 \mathrm{c}$ & $5 \cdot 08$ & - & - & - \\
\hline 1972 & 9396 & 1491 & $15 \cdot 9$ & $690 \mathrm{c}$ & $7 \cdot 34$ & - & - & - \\
\hline 1973 & 9309 & 1122 & $11 \cdot 8$ & $259 \mathrm{c}$ & $2 \cdot 78$ & - & - & - \\
\hline 1974 & 9195 & 601 & 6.5 & 232 & $2 \cdot 52$ & 540 & $5 \cdot 87$ & $43 \cdot 0$ \\
\hline 1975 & 12209 & 3060 & $25 \cdot 1$ & 928 & $7 \cdot 60$ & 1436 & $11 \cdot 76$ & $64 \cdot 6$ \\
\hline 1976 & 13372 & 2934 & $21 \cdot 9$ & 383 & $2 \cdot 86$ & 721 & $5 \cdot 39$ & $53 \cdot 1$ \\
\hline 1977 & 12250 & 2283 & $18 \cdot 6$ & 653 & $5 \cdot 33$ & 945 & $7 \cdot 71$ & $69 \cdot 1$ \\
\hline 1978 & 17266 & 2712 & $15 \cdot 7$ & 1031 & $5 \cdot 97$ & 1722 & $9 \cdot 97$ & $59 \cdot 9$ \\
\hline 1979 & 16262 & 2566 & $15 \cdot 8$ & 910 & $5 \cdot 60$ & 1483 & $9 \cdot 12$ & $61 \cdot 4$ \\
\hline 1980 & 17354 & 2727 & $15 \cdot 7$ & 615 & 3.54 & 1211 & 6.98 & $50 \cdot 8$ \\
\hline 1981 & 15872 & 2411 & $15 \cdot 2$ & 759 & $4 \cdot 78$ & 1321 & $8 \cdot 32$ & $57 \cdot 5$ \\
\hline 1982 & 17785 & 1598 & $9 \cdot 0$ & 512 & $2 \cdot 88$ & 1187 & $6 \cdot 67$ & $43 \cdot 1$ \\
\hline 1983 & 18559 & 2397 & $12 \cdot 9$ & 762 & $4 \cdot 11$ & 1304 & $7 \cdot 03$ & $58 \cdot 4$ \\
\hline 1984 & 16923 & 1945 & 11.5 & 599 & $3 \cdot 54$ & 1122 & $6 \cdot 63$ & $53 \cdot 4$ \\
\hline 1985 & 18716 & 1738 & $9 \cdot 3$ & 453 & $2 \cdot 42$ & 1062 & $5 \cdot 67$ & $42 \cdot 7$ \\
\hline 1986 & 19211 & 2063 & $10 \cdot 7$ & 253 & $1 \cdot 30$ & 573 & $2 \cdot 98$ & $44 \cdot 2$ \\
\hline 1987 & 20143 & 3282 & $16 \cdot 3$ & 710 & $3 \cdot 52$ & 1166 & $5 \cdot 78$ & $60 \cdot 9$ \\
\hline
\end{tabular}

depressions due to the annual low incidence in the summer season. The intervals between the top of the waves are regularly 4.5 years each in this 17 -year period (Fig. 1). The three low-incidence intervals between these first four waves are 14 trimesters each. The following fifth wave, however, culminated in 1975 , only 3 years after the last peak, with a low-incidence interval of only six trimesters. The next and last low-incidence interval was of five trimesters, terminated by a new early wave which had its maximum in the winter 1977-8. Since then each winter season has shown a relatively high incidence.

Analysis of the 9 years from 1978 to 1986 demonstrated only minor variations in the shape of the annual curves, but there were no significant changes in incidence from year to year (Fig. 1). While the annual number of sera investigated 
in these 9 years has varied around 17550 (range 15872-19211) with an increasing trend, the annual number of CF plus CA positive samples has shown an irregular decrease from 1031 in 1978 to 253 in 1986, and in this last year the lowest number of positive sera since 1974 when 232 were detected (Table 1).

Towards the end of the next year, 1987, a new epidemic developed, indicated by an almost fivefold increase in number of $\mathrm{CF} / \mathrm{CA}$ positive specimens from 52 in September to 255 in December. In the same period the total number of CF positive specimens (irrespective of CA titres) increased from 88 in September to 384 in December, and in February, 1988, the figure rose to 506 (not shown in Fig. 1 or Table 1). This is the highest monthly number of antibody positive specimens recorded in the 30-year period. An increase of this order of magnitude has only been observed at the beginning of previous epidemics. This epidemic is the first since that of $1977-8$.

The number of anti-M. pneumoniae plus CA positive sera made up about half of the total anti-M. pneumoniae positive sera. In the period 1974-87 the average was $54 \cdot 4 \%$ (range $42 \cdot 7-69 \cdot 1 \%$ ). Generally the ratio was high when the total number of anti-M. pneumoniae positive sera was high (Table 1).

If a curve showing the number of $\mathrm{CF}$ plus $\mathrm{CA}$ positive sera each month were to be superimposed on a curve showing the total number of $\mathrm{CF}$ positive sera (irrespective of CA test result) each month, the two curves would run closely in parallel and the peaks of the waves would coincide exactly.

All these data are based on results from testing single serum samples. Since more samples are generally received from seropositive than from seronegative patients (Lind \& Bentzon, 1976), it is possible that high incidence waves of positive sera may exaggerate the reflection of positive cases, but the time when the curves peak is not likely to be much displaced from the culmination of outbreaks.

We have therefore compared these data with the number of seropositive patients each month from January 1973 to December 1987. In this exercise seropositivity was defined by either a $\geqslant$ fourfold rise in titre in the anti- $M$ pneumoniae CF test, or a CF titre of $\geqslant 512$, or a CF titre plus CA titre both of $\geqslant 64$. The curve showing the number of these patients each trimester is closely in parallel with that of the above-mentioned curve for serum specimens, with coincidence of their peaks.

\section{DISCUSSION}

The prerequisite for an estimation of the varying incidences of $M$. pneumoniae infection has been the investigation of CA positive sera for antibodies to $M$. pneumoniae. Since a rise in titre of the specific antibodies has not consistently been recorded in our patients we have had to rely on testing single sera. It has been well documented that while the specific antibodies may be demonstrated at a positive level for several months to more than a year after a $M$. pneumoniae infection, the occurrence of CA is of much shorter duration. Usually, CA appear transiently at a positive level from the second week till 1 or 2 months after onset of $M$. pneumoniae illness (Rytel, 1964; Fernald,, Clyde \& Denny, 1967; Biberfeld, 1971). Therefore, the simultaneous occurrence of CA and the specific antibodies in a blood specimen indicates a current or recent $M$. pneumoniae infection of the 
Table 2. Number of children registered in day-care institutions and day care in private homes in Denmark 1961-86

$\begin{array}{ccccc} & \begin{array}{c}\text { Day } \\ \text { nurseries* }\end{array} & \begin{array}{c}\text { Day-care } \\ \text { institutions } \dagger\end{array} & \begin{array}{c}\text { Day care in } \\ \text { private homes }\end{array} & \text { Total } \\ 1961 & 4 \cdot 358 & 38 \cdot 458 & - & 42 \cdot 816 \\ 1965 & 4 \cdot 690 & 44 \cdot 079 & - & 48 \cdot 769 \\ 1970 & 9 \cdot 132 & 69 \cdot 852 & 6 \cdot 397 & 85 \cdot 381 \\ 1975 & 17 \cdot 088 & 121 \cdot 719 & 23 \cdot 840 & 162 \cdot 647 \\ 1980 & 19 \cdot 470 & 164 \cdot 308 & 61 \cdot 418 & 245 \cdot 196 \\ 1986 & 21 \cdot 615 & 183 \cdot 040 & 61 \cdot 779 & 266 \cdot 434\end{array}$

* 0 - to 2-year-old children.

$\dagger$ including kindergartens, recreation centres and age-integrated institutions (3- to 14-yearold children).

patient. Although CA as a non-specific manifestation may develop also during respiratory infections caused by other agents (e.g. adenovirus and influenza virus) their association with $M$. pneumoniae infection is much more common (Chanock et al. 1961; Mufson et al. 1962; Lind, Ravn \& Møller, 1970).

It also appears from the above cited studies as from the present investigation (Table 1) that CA develop in only about half of patients with a positive test for $M$. pneumoniae antibodies, a proportion which apparently has not changed over the years. It therefore seems justified to assume that the major waves showing high incidences of sera with these concurrently positive tests closely depict epidemics of $M$. pneumoniae infection. For this reason and for the sake of creating a uniform serological basis for the entire longitudinal study, a positive CA test was chosen as an inclusion criterion for the whole material.

The present study has shown a remarkable shift in the previously reported regular pattern of epidemics culminating every 4.5 years during the period 1958-74. The 'premature' epidemics in 1975 and 1977-8 seem to have inaugurated a change from epidemic to endemic occurrence of $M$. pneumoniae infection in Denmark. Since the winter 1977-8, each winter has shown a relatively high incidence over each of the following 9 years till 1986 (Fig. 1 and Table 1). The shape of the annual seasonal waves in these years has shown minor variations, but the incidences have varied significantly from year to year with an obvious trend of decrease which ended in 1986 with the lowest incidence since 1974. This trend must be evaluated against the background of a slightly varying but significant increase in number of specimens received over these 9 years, during which a significant decrease in the percentage of seropositive samples has been observed (Table 1). Towards the end of 1987 a large new epidemic began, when the highest monthly number of positive specimens ever were recorded in this laboratory. Clearly a second remarkable shift in the epidemiological pattern had occurred.

The factors that govern the observed periodicity of $M$. pneumoniae epidemics or the remarkable changes therein are not known. The communicability and transmission of the infection and the immunity of the host have been extensively studied (Clyde, 1979; Denny, Clyde \& Glezen, 1971) but their possible role in outbreaks or epidemics of the disease in a whole population is unresolved. 
The authors advance the hypothesis that one factor which may have contributed to the first change in the epidemiological pattern in this country is the number of children in day care institutions and day care in private homes. From 1961 to 1986 this number has increased more than sixfold. The increase was most steep in the years of change from an epidemic to an endemic situation (Table 2). The children are from 0 to 14 years old, but only a very limited number are above the age of 10. This means that today almost one quarter of this age group (which make up about 1 million out of the 5.1 million population) is in day care (Bertelsen, 1987). A natural consequence would be an increasing risk of transmission of $M$. pneumoniae infection in this highly exposed risk group and in the children's families. The resulting increasing number of individuals with acquired protective immunity would tend to reduce the number of infectious cases prevalent. However, pari passu with the termination of effective protective immunity, which may last between 1.5 and 10 years (Fernald, Collier \& Clyde, 1975; Foy et al. 1977) the balance may have tipped, giving the relatively few remaining prevalent cases the opportunity to spread sufficiently to develop into the new epidemic of the winter 1987-8. Foy et al. estimated that after a time lapse of 3-5 years $M$. pneumoniae pneumonia occurs as frequently in patients formerly infected with $M$. pneumoniae as in the general population.

We have no information about the true incidence of $M$. pneumoniae infection in the population. Several factors may influence our data, some of which have been discussed previously (Lind \& Bentzon, 1976). A major but unassessed factor is the interest among physicians in the diagnosis of $M$. pneumoniae infection which may have increased at least during the first two decades since the $1960 \mathrm{~s}$, when the aetiological significance of $M$. pneumoniae in primary atypical pneumonia became established (Clyde, 1979). This factor may influence the actual number of specimens sent for serodiagnosis, which again may increase when physicians are aware of an epidemic, resulting probably in a relative increase in seropositive results. However, it is difficult to conceive how this might influence the time when an epidemic will reach a maximum.

The CF test for $M$. pneumoniae antibodies which has been used since 1970 has been equilibrated by inclusion of pools of human reference sera to maintain its sensitivity, and the same hold true for the CA test.

Wild strains of M. pneumoniae isolated in this country between 1962 and 1985 showed the same profile when compared by sodium dodecyl sulphate polyacrylamide gel electrophoresis. In cross-over tests by Western Blotting with sera from the patients from whom the strains were isolated, no evidence of antigenic drift was found over this 23-year period (Søndergård-Andersen \& Lind unpublished study, 1987). Similar observations were made in the USA over a 10year period ( $\mathrm{Vu}$ et al. 1987). However, we have no information about possible changes in virulence of wild strains.

Long-term studies of the infection in other populations have indicated a periodicity of 3-6 years for major outbreaks or epidemics (Chanock et al. 1967; Evans, Allen \& Sueltmann, 1967; Glezen et al. 1971; Joosting et al. 1976; Foy et al. 1979 ; Denny, Clyde \& Glezen, 1971). Niitu et al. (1982) has conducted a study over 22 years (1960-82) among pupils of the primary, middle, and high schools in Sendai, Japan, which showed a strictly 4-year periodicity. 
Publications from parts of Europe since 1967 have described the following major outbreaks or epidemics of $M$. pneumoniae infection: in Czechoslovakia 1962-3 (Soběslavský et al. 1970), in Holland 1965-6 (Hers \& Masurel, 1967), in Italy 1971-2 and 1975 (Martelli et al. 1976), and in the German Democratic Republic 1974-5 and 1979-80 (Ortel, Hermsdorf \& Bender, 1979; Bretschneider, Witzleb \& Witzleb, 1979; Ritter, Nicklisch \& Lange, 1983; Handrick et al. 1987).

In laboratory reports on $M$ pneumoniae infections in England and Wales 1970-86 a regular cyclic pattern with an epidemic culminating every 4 years was seen, the first one occurring in 1971-2 (Anonymous, 1986; Anonymous, 1987).

In Norway, case reports were few from 1967 to 1971. A small peak was seen in 1972 concurrently with a Danish peak. A sharp increase occurred in the third trimester of 1975, three trimesters later than in Denmark. Thereafter there were relatively high incidences in 1982 and 1983, and again in 1986 and 1987. However, since 1975 there has been no regular epidemiological pattern (Flugsrud, 1987).

According to Jansson, Essen \& Tuuri (1971), Helsinki in Finland experience two outbreaks of $M$. pneumoniae pneumonia, one in the winter 1962-3, the other 1967-8. Monthly reports of serologically confirmed cases from different laboratories in Finland from 1971 to 1987 (Kleemola, 1987) show increases in the incidence in the winter 1972-3 and again in 1977-8. Between these two peaks there were no regular variations. From April 1978 till November 1981 the incidence was rather low. Since then the epidemiological pattern has resembled that in Denmark with varying high incidences in the winter seasons.

It is interesting that the regular cyclic pattern seen in England and Wales up to the end of 1986 has not occurred in Norway, Finland or Denmark over the 11 years since 1975 .

\section{REFERENCES}

Anonymous (1986). Monthly report from the PHLS Communicable Disease Surveillance Centre. British Medical Journal 292, 889.

Anony mous (1987). Report from the PHLS Communicable Disease Surveillance Centre. British Medical Journal 294, 361-362.

Bertelsen, O. (1987). The Danish National Institute of Social Research. Personal communication.

BIBERFELD, G. (1971). Antibody responses in Mycoplasma pneumoniae infection in relation to serum immunoglobulins, especially IgM. Acta Pathologica Microbiologica Scandinavica, Section B 79, 615-629.

Bretschneider, R., Witzleb, W. \& Witzleb, H. (1979). Einige epidemiologische und klinische Aspekte der Mycoplasma pneumoniae-Infektionen im Kindesalter. Deutsches GesundheitsWesen 34, 1756-1763.

Chanock, R. M., Fox, H. H., James, W. D., Gutekunst, R. R., White, R. J. \& Senterfit, L. B. (1967). Epidemiology of M. pneumoniae infection in military recruits. Annals of the New York Academy of Sciences 143, 484-496.

Chanock, R. M., Mufson, M. A., Bloom, H. H., James, W. D., Fox, H. H. \& Kingston, J. R. (1961). Eaton agent pneumonia. Journal of the American Medical Association 175, 213-220.

CLYDE, W. A. JR. (1979). Mycoplasma pneumoniae infections of man. In The Mycoplasmas, vol. II (ed. J. G. Tully and R. F. Whitcomb), pp. 275-303. New York: Academic Press.

Denny, F. W., Clyde, W. A. JR., \& Glezen, W. P. (1971). Mycoplasma pneumoniae disease: clinical spectum, pathophysiology, epidemiology, and control. The Journal of Infectious Diseases 123, 74-92.

Eaton, M. D., Meiklejohm, (i. \& Van Herick, W. (1944). Studies on the etiology of primary 
atypical pneumonia. A filterable agent transmissible to cotton rats, hamsters and chick embryos. Journal of Experimental Medicine 79, 649-668.

Evans, A. S., Allen, V. \& Sueltmann, S. (1967). Mycoplasma pneumoniae infections in university of Wisconsin students. American Review of Respiratory Disease 96, 237-244.

Fernald, G. W., Clyde, W. A. Jr. \& Denny, F. W. (1967). Nature of the immune response to Mycoplasma pneumoniae. Journal of Immunology 98, 1028-1038.

Fernald, G. W., Collier, A. M. \& Clyde, W. A. Jr. (1975). Respiratory infections due to Mycoplasma pneumoniae in infants and children. Pediatrics 55, 327-335.

FlugsRud, L. B. (1987). Monthly report of positive findings from virological laboratories. Department of Virology, National Institute for Public Health, Oslo, Norway. Personal communication.

Foy, H. M., Cooney, M. K., Allan, I. \& Kenny, G. E. (1979). Rates of pneumonia during influenza epidemics in Seattle, 1964 to 1975. Journal of the American Medical Association 241, $253-258$.

Foy, H. M., Kenny, G. E., Sefi, R., Ochs, H. D. \& Allan, I. D. (1977). Second attacks of pneumonia due to Mycoplasma pneumoniae. The Journal of Infectious Diseases 135, 673-677.

Glezen, W. P., Loda, F. A., Clyde, W. A. Jr., Senior, R. J., Sheaffer, C. I., Conley, W. G. \& DenNy, F. W. (1971). Epidemiologic patterns of acute lower respiratory disease of children in a pediatric group practice. The Journal of Pediatrics 78, 397-406.

Handrick, W., Heinze, M., Winter, R., Lange, R. \& Rudolf, D. (1987). Infections due to Mycoplasma pneumoniae in children and adolescents. Zeitschrift für Erkrankungen der Atmungsorgane 168, 59-65.

Hers, J. F. P. \& Masurel, N. (1967). Infection with Mycoplasma pneumoniae in civilians in the Netherlands. Annals of the New York Academy of Sciences 143, 447-460.

Jansson, E., Von Essen, R. \& TuURI, S. (1971). Mycoplasma pneumoniae pneumonia in Helsinki 1962-1970. Scandinavian Journal of Infectious Diseases 3, 51-54.

Joosting, A. C. C., Harwin, R. M., Coppin, A., Battaglia, P.\& Van der Hoef, P. (1976). A serological investigation of Mycoplasma pneumoniae infection on the Witwatersrand. South African Medical Journal 50, 2134-2135.

KenNy, G. E. \& GRAYston, J. T. (1965). Eaton pleuropneumonia-like organism (Mycoplasma pneumoniae) complement-fixing antigen: Extraction with organic solvents. Journal of Immunology 95, 19-25.

Kleemola, M. (1987). National Public Health Institute, Helsinki, Finland. Personal communication.

Lind, K. (1968). Immunological relationships between Mycoplasma pneumoniae and Streptococcus MG. Acta Pathologica Microbiologica Scandinavica 73, 237-244.

LinD, K. (1971). Incidence of Mycoplasma pneumoniae infection in Denmark from 1958 to 1969. Acta Pathologica Microbiologica Scandinavica, Section B 79, 239-247.

Lind, K. \& Bentzon, M. W. (1976). Epidemics of Mycoplasma pneumoniae infection in Denmark from 1958 to 1974. International Journal of Epidemiology 5, 267-277.

Lind, K., Mansa, B. \& Olesen, H. (1963). Pencillamine treatment in the cold-haemagglutinin syndrome. Acta Medica Scandinavica 173, 647-660.

Lind, K., Ravn, T. J. \& Møller, J. (1970). Occurrence of Mycoplasma pneumoniae infection in patients hospitalized with acute respiratory illness. Acta Pathologica Microbiologica Scandinavica, Section B 78, 6-14.

Martelli, A., Vegis, D., Milanino, T. \& Monteverde, A. (1976). The Mycoplasma pneumoniae in pathological respiratory processes. Serological disease. Annali Sclavo 18, 260-267.

Murson, M. A., Bloom, H. H., Manko, M. A., Kingston, J. R. \& Chanock, R. M. (1962). V. Eaton agent: A review. American Journal of Public Health 52, 925-932.

Nituv, Y., Suzaki, K., Miyaji, T., Horikawa, M., Komatsu, S., Terasawsa, M. \& Suetake, T. (1982). Strictly four-year periodicity of outbreaks of $M$. pneumoniae infections and antibiotic sensitivity of $M$. pneumoniae isolates in Sendai. Proceedings of the 4 th International Congress of the International Organization for Mycoplasmology, pp. 52. Tokyo.

Ortel, S. von, Hermsdorf, S. \& Bender, U. (1979). Experience gathered with a measuring network programme for monitoring acute respiratory disease. Zeitschrift für die Gesamte Hygiene und ihre Grenzgebiete 25, 608-612.

Ritter, E., Nicklisch, W. \& Lange, A. (1983). Study about infections with Mycoplasma pneumoniae of out-patients with respiraţory infections. Zeitschrift für die Gesamte Hygiene und ihre Grenzgebiete 29, 435-438. 
Rytel, M. W. (1964). Primary atypical pneumonia: Current concepts. American Journal of Medical Science 247, 84-104.

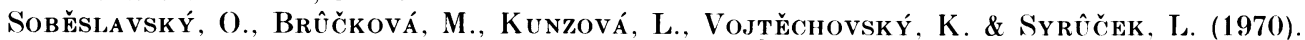
Adenovirus, RS virus and $M$. pneumoniae infections in young population of Prague in 1962-67. Journal of Hygiene, Epidemiology, Microbiology and Immunology 14, 350-359.

Vu, A. C., Foy, H. M., Cartwright, F. D. \& Kenny, (x. E. (1987). The principal protein antigens of wild isolates of Mycoplasma pneumoniae as measured by human serum IgG antibodies are stable in strains collected over a ten-year period. Infection and Immunity 55, 1830-1836. 